\title{
Presidential review of the year's activity 1994-5
}

A year in the life of the President of the British Society of Gastroenterology passes very rapidly. During my term of office a number of old, perennial issues have been revisited but additionally new important initiatives have been planned for the Society.

We continue to question the frequency, role, and strategy of the twice yearly meetings that the Society holds. What is our attitude to European Gastroenterology and how should this influence our meetings? There are no easy answers and the Society remains divided. I shall return to this topic.

It is important that our Society reflects the wide diversity of gastroenterology practice and research. We have met the challenge by creating Sections that reflect specialty interests within our membership, both organ interests as well as the practice of various technical disciplines. Having Sections has, determined in turn, the structure and membership of our Council and its sub-committees. During my time the role of the Sections has been reevaluated; we have questioned their need and whether the Society is best served by the current Sections. The discussions have taken place inside and outside Council. It is clear to me that the membership of our Society are content with an organisational structure based on Sections although there is room for some adjustment to their number and interest; and these have been made. The American philosopher John Dewey wrote that old ideas give way slowly. He believed that progress usually occurs through sheer abandonment of some questions because of their decreasing vitality and a change of urgent interest. I am sure that both the number of meetings and sectional structure will cease to be issues for debate as they are succumbed into other more pressing issues that are manifesting for the Society.

As the British Society of Gastroenterology moves into the 21 st century pressures are emerging that require to be responded to now: changes in the National Health Service, changes in universities and research, changes in gastroenterological practice, and the need for continuing medical education. The present structure of the British Society of Gastroenterology and the nature of its constitution make change a slow process. But we cannot wait for events to overtake us. Recently I formed a strategic working party to anticipate the ways in which our Society should respond to the challenges of the next two decades. It is appropriate that I summarise some of the suggestions that the working party made. These have been presented to Council as well as to the Annual Business Meeting of the Society.

Seven key areas for future strategic planning have been identified, which are, in order of priority, standards, research, education, relations with European Gastroenterology, training, influence with the lay public, and the involvement of patients and public in the activities of the British Society of Gastroenterology.
It will be possible to implement some of the recommendations immediately; action on others will require more time. Thus before the end of 1995 it should be possible to establish a Standards Committee for the purpose of improving the clinical practice of gastroenterology, and define and maintain standards for all professions related to gastroenterology. The committee will work closely with the Education Committee over standards for education and training. Prompt action can also be taken to enhance the existing structure of the Education Committee to enable it to deal with the programme requirements of Society meetings, to play an active part in postgraduate courses, to develop modern techniques for distant learning, and to support international, European and local gastroenterological meetings. The Research Committee will assume increased prominence and its remits must be revised. The committee should interact with National Research Councils and other bodies supporting gastroenterological research. The committee should have a role in coordinating multicentre research especially for evidence based practice; it should promote research and training programmes.

The society must work vigorously to ensure that its aims and those of the British Digestive Foundation coincide and that the two organisations work smoothly towards the twin goals of fundraising to support gastroenterological research and educating the public about gastrointestinal health and disease. Dr Paul Smith and I have had useful discussions with Professor John Lennard-Jones to ensure that the BSG and BDF share common goals and work closely to achieve these.

Plans have been laid to establish a European policy group to advise Council over its European strategy including support for European meetings. An external relations group is also proposed for the purpose of relating to Government, Health Departments, and patients and consumers. It is envisaged that it will work closely with the BDF. It will be useful to establish a new financial advisory group. Importantly there is a proposal that there should be lay involvement in all major BSG committees including Council.

Change always excites a varied response ranging from enthusiastic acceptance to contemptuous dismissal. Whatever the vested interests that are challenged, whatever the insecurities that are exposed, I hope that the membership of our Society will appreciate that the strategic plan has emerged following a genuine and open minded attempt to ensure that our Society will be best prepared to meet the challenges of the 21 st century.

Department of Medicine,

IAN A D BOUCHIER

The Royal Infirmary,

Lauriston Place,

Edinburgh EH3 9YW 